\title{
Factors associated with Patients' Incomplete Understanding of Prescriptions
}

\author{
Gerard Raimon M. Saranza, ${ }^{1}$ Derick Erl P. Sumalapao ${ }^{1,2}$ and Isidro C. Sia ${ }^{1}$ \\ ${ }^{1}$ Department of Pharmacology and Toxicology, College of Medicine, University of the Philippines Manila \\ ${ }^{2}$ Department of Physical Sciences and Mathematics, College of Arts and Sciences, University of the Philippines Manila
}

\begin{abstract}
Background. Patients' understanding of prescriptions is one of the key elements to a successful treatment. In the Philippines, patients do not have the benefit of having pharmacists explaining the prescription when they purchase their medicines. Inability to understand and follow prescriptions may, therefore, contribute to medication non-compliance, which leads to unwanted disease progression, complications, and even premature death.
\end{abstract}

Objectives. To assess the understanding of Filipino patients of prescriptions given by their doctors and to identify the factors that significantly affect their understanding.

Methods. In total, 392 individuals, using purposive sampling, were interviewed from pharmacies around a government hospital outpatient department (OPD), a private hospital OPD, private clinics, and local health centers in Manila, Philippines. The patients' knowledge about the proper intake of the prescribed drugs was assessed and the factors that were deemed to affect their understanding were then identified. Crude odds ratios (ORs) and 95\% confidence intervals (Cls) were calculated according to the various study factors included in the study to measure the association between each study variable and incomplete understanding of prescriptions. A multivariate logistic regression model was constructed applying a stepwise procedure to enter variables in the model.

Results. Among the 392 participants, 219 (55.9\%) patients had an incomplete understanding of prescriptions, 176 (44.9\%) were not able to identify the correct dose of the prescribed drug, followed by 103 (26.3\%) who were not able to identify the name of the drug. Multivariate logistic regression analysis identified only three independent variables to be statistically significant predisposing factors to incomplete understanding of prescriptions: non-legible prescriptions $(\mathrm{OR}=4.598,95 \% \mathrm{Cl}$

Poster Presented at the 3rd International Conference for Improving Use of Medicines (ICIUM), November 14-18, 2011, Antalya, Turkey.

Paper won 2nd place at the Annual Intern's Research Forum, April 24, 2012, College of Medicine, University of the Philippines Manila.

Corresponding Author: Gerard Raimon M. Saranza, MD

Section of Adult Neurology

Department of Neurosciences

Philippine General Hospital

University of the Philippines Manila

Taft Avenue, Ermita, Manila 1000 Philippines

Telephone: +632 5548400 local 2401 or 2405

Email: gerardsaranza@gmail.com
2.671-7.913), prescriptions with an incomplete set of written instructions ( $\mathrm{OR}=2.108,95 \% \mathrm{Cl} 1.234-3.601)$, and patient having had no previous use of the prescribed drug or a similar drug $(\mathrm{OR}=2.126,95 \% \mathrm{Cl}$ 1.361-3.320).

Conclusions. The results of this study suggest that physicians play an important role in promoting complete understanding of prescriptions. Non-legible prescriptions and prescriptions with an incomplete set of written instructions were found to significantly affect patients' understanding of prescriptions. Physicians should also be more careful in instructing patients who will take the prescribed medications for the first time. These information may be used to enhance better understanding of prescriptions among patients and thereby prevent noncompliance and treatment failure.

Key Words: understanding of prescriptions, prescriptions, compliance, non-compliance

\section{Introduction}

Compliance is defined as the extent to which patients take medications as prescribed by their health care providers. ${ }^{1}$ According to the World Health Organization (WHO), only about 50 percent of patients take their medications as prescribed by their doctor. ${ }^{2}$ WHO consequently recognizes medication non-compliance as a worldwide problem which should be addressed seriously by all health care providers and policy makers.

Several studies have already been conducted regarding the factors which contribute to medication non-compliance and these include socio-demographic factors, health system related factors, therapy-related factors, condition-related factors and patient-related factors. These studies have demonstrated that non-compliance affects all ages, both sexes and all levels of educational attainment and socioeconomic status. ${ }^{3}$

One of the important factors identified is the inability to understand the instructions regarding the intake of a prescribed drug. Lau et al. has shown in their study that there is a close relationship between treatment compliance and a clear understanding of prescriptions. ${ }^{4}$ In a recent study conducted by Davis et al., patient's understanding of prescription label instructions ranged from 53\% - 89\% of 10 common prescription label instructions. ${ }^{5}$ In another study conducted by Gottlieb, 60 percent or more of patients could not correctly report what their physicians told them about medication use 10 to 80 minutes after receiving the 
information. ${ }^{6}$ In America, it is estimated that more than 90 million Americans cannot understand basic health information. ${ }^{7}$ There are no such similar studies conducted locally. The nearest study would be that of Hardon wherein the median number of antibiotics dispensed in pharmacies was six tablets or capsules, indicating a widespread lack of understanding of proper drug intake. ${ }^{8,9}$ In another local study conducted by Lansang et al., antimicrobial purchases in a district in Manila were made without prescription in $66.3 \%$ of 1608 transactions and that almost $90 \%$ of purchases were for 10 or less capsules or tablets. ${ }^{10}$ Customers with written prescriptions purchased a mean of 8 while those who self-prescribed purchased a mean of 4 units. The authors concluded that these practices can provide only limited clinical efficacy and favor the emergence of resistant bacteria. Furthermore, based on the researchers' experience at the Outpatient Department of the Philippine General Hospital, there were already several instances when followup patients show no improvement in their health status all because of a lack of understanding on the proper intake of their medications.

Lack of medication adherence has serious ramifications which range from unnecessary disease progression, disease complications, reduced functional abilities, a lower quality of life to premature death. These unwanted end results of medication non-compliance do not only affect one individual but the entire health care system as well, with all the economic burden that it will bring. ${ }^{11}$

This study assessed the understanding of Filipino patients regarding the drugs prescribed by their doctors as a specific patient-related factor, which contributes to noncompliance. In addition, this study identified the factors which significantly affect the patients' understanding of prescriptions. The factors included in this study were classified under three major categories: (1) patient-related factors, (2) physician-related factors and (3) prescriptionrelated factors. Moreover, the populations at risk were also ascertained so that whatever strategies will be undertaken by the government to address this problem of noncompliance in the future, emphasis will be given to these vulnerable populations. If the patients' understanding of prescriptions is to be improved, various social, economic, and medical factors must be identified and addressed thereafter.

\section{Methods}

\section{Study Population}

The population in this study included individuals 18 years of age and older who consulted a physician and were given prescriptions. These patients should also selfadminister the drug prescribed without any form of assistance from a family member or a caretaker. Prior to the interview, all respondents were asked to read and sign an Informed Consent Form, available in both in English and in
Tagalog. The study was also thoroughly explained to the respondents by the interviewer. Patients did not receive any reward- be it monetary or in kind. They were, however, given a chance to ask questions about the drugs they are taking and were answered by the interviewers to the best of their abilities.

A total of 392 individuals were purposively sampled and interviewed from June to August, 2010, after the study received an approval from the Research Implementation and Development Office (RIDO) of the UP College of Medicine. The sample size was determined using the formula: $n=\left[\frac{p(1-p)}{0.05^{2}}\right] 1.96^{2}$ where 0.05 is the margin of error and $\mathrm{p}=0.5$ is the assumed proportion of individuals with a complete knowledge of the proper intake of a prescribed drug since to date, there are no available similar studies done locally. This value for $\mathrm{p}$ will yield the maximum sample size $(\mathrm{n}=385)$.

The researchers allocated the 392 respondents equally into four subgroups: patients who sought consult in a government hospital (98 respondents), private hospital (98 respondents), local health centers (98 respondents) and private clinics (98 respondents). The subgroups were based on the four major sources of outpatient prescriptions in the country.

The researchers conducted the interview in the following 11 drugstores or pharmacies: PGH Pharmacy (53 samples), 3 Drug Stores in front of PGH (62 samples), 1 Mercury Drug Store along Taft Avenue (58 samples), 1 Drug Store in UN Avenue (32 samples), UST Pharmacy (38 samples), 1 Mercury Drug Store near UST Hospital (48 samples), 1 Mercury Drug Store in Bambang (22 samples), Pharmacies/Botika ng Bayan near San Pablo Health Center (41 samples) and Pharmacies/Botika ng Bayan near Malibay Health Center (38 samples). These pharmacies were randomly selected to capture patients who consulted at the Philippine General Hospital, Jose Reyes Memorial Medical Center, Ospital ng Maynila, Medical Center Manila, Manila Doctors Hospital, University of Sto. Tomas Hospital, Chinese General Hospital, neighboring private clinics and local health centers. Mercury Drugstore outlets were chosen primarily in this study since Mercury Drug is estimated to sell as much as 60 percent of all medicines sold each year in the Philippines. ${ }^{12,13}$

\section{Data Collection and Variables}

A researcher-structured questionnaire (Appendix) was administered in the study to assess the patients' understanding of prescribed drugs. The questionnaire was constructed based on several studies done abroad. No pilot testing was done; however, the results of this study could be used as benchmark for future studies. During the conduct of the interview, it was the interviewers, and not the respondent, who filled out the questionnaire. The interviewers convened to standardize definitions and manner of questioning. All 
clarifications during the actual conduct of the interview were addressed by the authors who were present on-site.

For a given pharmacy, every third patient purchasing a prescribed drug/s was considered in the sampling population until the desired sample size for a particular study group was obtained. All respondents were interviewed in one corner of the pharmacy to maintain privacy and confidentiality.

In this study, Complete Understanding is defined as knowing all of the following essential information of the prescribed drug: name (either generic name or brand name or both), formulation, dose, frequency, duration, and route of administration. On the other hand, Incomplete Understanding, is designated if the patient misses at least one of the parameters stated above.

The factors which were deemed to affect the level of understanding of the prescribed drugs were then identified. Patient-related factors include the age, sex, educational attainment, civil status, occupation, an experience of assisting in the administration of a drug to another person, intake of medications other than the prescribed drug/s, a previous history of use of the same or similar drug, and the number of drugs prescribed.

Physician-related factors included in the study were the following: whether the physician is a general practitioner or a specialist and the place of consult.

Prescription related factors included: the manner by which the physician give out prescription, legibility of the doctor's handwriting, whether the prescription contained all the necessary information mandated by the law (RA 9521), and whether it contained a complete set of written instructions regarding proper drug intake.

\section{Statistical Analysis}

A descriptive analysis was carried out to determine the proportion of patients who have an Incomplete Understanding of the prescribed drug. Crude odds ratios and $95 \%$ confidence intervals were calculated according to the various study factors mentioned to measure the association between each study variable and inability to understand prescriptions. A multivariate logistic regression model was constructed applying a stepwise procedure to enter variables in the model. The model included independent variables that were statistically significant at the a priori level of 0.05 . Presence of multicolinearity was assessed and if it existed between two variables, the variable showing the stronger association with the inability to understand the prescribed drug was retained in the model. The analyses was conducted using SPSS version 16.

\section{Ethical Issues}

This study was conducted in accordance with the Declaration of Helsinki for biomedical research involving human subjects. No respondent was coerced to be a part of the study and confidentiality and privacy were observed all throughout the conduct of the study. A respondent was allowed to terminate participation anytime for any reason. All respondents who voluntarily expressed their intention to participate in the study were able to complete the interview.

In circumstances wherein respondents were found to have a misunderstanding of a prescription, they were advised appropriately by the researchers.

All results obtained in this study were handled with confidentiality. The questionnaires were secured by one of the authors in a locked cabinet. Data were encoded in a room where no other individuals aside from the researchers can visualize the laptop monitor or the questionnaires. The laptop was secured with a password and all electronic documents were secured with a password that only the researchers can access.

\section{Results}

The mean age of the study population is 45.5 years (SD 16.93) and out of the 392 participants in the study, $229(58.4 \%)$ were included in the age group 18-50 years old (Table 1). The study population was predominantly female $(70.2 \%)$ and was well educated with $87.5 \%$ of patients having at least a high school education. Majority of the participants were married $(67.3 \%)$ and with a large proportion of the population being unemployed (67.1\%). Only $162(41.3 \%)$ participants reported use of other medications and $277(70.7 \%)$ had an experience of drug administration to another patient. There were 180 (45.9\%) patients in the study population currently taking a single drug and $185(47.2 \%)$ patients had previous use of the same or similar prescribed drug.

Only a quarter $(25.3 \%)$ of the total participants sought consult among general practitioners and the remaining $74.7 \%$ consulted specialists. There were four places of consult in this study with equal allocation of participants, and they all reported to have received both verbal and written instructions.

Most of these patients either had a single prescription with a single drug prescribed $(45.9 \%)$ or had a single prescription with multiple drugs prescribed (38.3\%). Majority of the participants found the prescription legible $(71.4 \%)$. It was also found out that $77.0 \%$ of the prescriptions did not conform to the provisions of the law and $78.6 \%$ of these prescriptions did not contain a complete set of written instructions regarding proper intake of the prescribed drug.

Among the 392 participants, 219(55.9\%) patients had an incomplete understanding of prescriptions, 176(44.9\%) were not able to identify the correct dose of the prescribed drug, followed by $103(26.3 \%)$ who were not able to identify the name of the drug. Only $60(15.3 \%)$ participants did not identify the duration of drug administration, $34(8.7 \%)$ did not specify frequency, $14(3.6 \%)$ did not understand formulation and $10(2.6 \%)$ did not recognize the correct route of administration (Table 2). 
Table 1. Characteristics of Participants Regarding Incomplete Understanding of Prescriptions (n=392).

\begin{tabular}{|c|c|c|c|c|c|c|c|}
\hline Categorical Predisposing Factors & $\begin{array}{l}\text { Total } \\
=392\end{array}$ & $(\%)$ & $\begin{array}{l}\text { Number of Patients } \\
\text { with Incomplete } \\
\text { Understanding } \\
(\mathrm{n}=219)\end{array}$ & $(\%)$ & p-value & $\begin{array}{l}\text { Odds } \\
\text { Ratio }\end{array}$ & $\begin{array}{l}\text { 95\% Confidence } \\
\text { Interval }\end{array}$ \\
\hline \multicolumn{8}{|l|}{ PATIENT RELATED FACTORS } \\
\hline \multicolumn{8}{|l|}{ Age } \\
\hline $18-50$ & 229 & 58.4 & 133 & 58.1 & - & 1 & - \\
\hline $51-60$ & 80 & 20.4 & 37 & 46.3 & 0.83 & 0.924 & $0.447-1.908$ \\
\hline $61-70$ & 48 & 12.2 & 28 & 58.3 & 0.177 & 0.574 & $0.256-1.285$ \\
\hline 71 and above & 35 & 8.9 & 21 & 60 & 0.879 & 0.933 & $0.384-2.266$ \\
\hline \multicolumn{8}{|l|}{ Sex } \\
\hline Male & 117 & 29.8 & 70 & 59.8 & - & 1 & - \\
\hline Female & 275 & 70.2 & 149 & 54.2 & 0.303 & 0.794 & $0.512-1.232$ \\
\hline \multicolumn{8}{|l|}{ Highest Educational Attainment } \\
\hline College & 195 & 49.7 & 97 & 49.7 & - & 1 & - \\
\hline High School & 148 & 37.8 & 88 & 59.5 & 0.586 & 0.005 & $0.000-733642.3$ \\
\hline Elementary & 47 & 12 & 32 & 68.1 & 0.614 & 0.008 & $0.000-1087941$ \\
\hline None/Illiterate & 2 & 0.5 & 2 & 100 & 0.642 & 0.012 & $0.000-1593850$ \\
\hline \multicolumn{8}{|l|}{ Civil Status } \\
\hline Married & 264 & 67.3 & 140 & 53 & - & 1 & - \\
\hline Single & 65 & 16.6 & 40 & 61.5 & $0.042^{*}$ & 0.396 & $0.162-.0 .967$ \\
\hline Separated & 12 & 3.1 & 8 & 66.7 & 0.255 & 0.561 & $0.207-1.517$ \\
\hline Widow/Widower & 24 & 6.1 & 11 & 45.8 & 0.637 & 0.701 & $0.160-3.070$ \\
\hline Live-in & 27 & 6.9 & 20 & 74.1 & $0.043^{*}$ & 0.297 & $0.091-0.962$ \\
\hline \multicolumn{8}{|l|}{ Occupation } \\
\hline None & 263 & 67.1 & 143 & 54.4 & - & 1 & - \\
\hline Employed & 129 & 32.9 & 76 & 58.9 & 0.395 & 1.203 & $0.786-1.843$ \\
\hline \multicolumn{8}{|l|}{ Experience of Administering Drug to Another Patient } \\
\hline Yes & 277 & 70.7 & 147 & 53.1 & - & 1 & - \\
\hline No & 115 & 29.3 & 72 & 62.6 & 0.084 & 1.481 & $0.949-2.312$ \\
\hline \multicolumn{8}{|l|}{ Use of Other Drugs } \\
\hline Yes & 162 & 41.3 & 86 & 53.1 & - & 1 & - \\
\hline No & 230 & 58.7 & 133 & 57.8 & 0.352 & 1.212 & $0.809-1.816$ \\
\hline \multicolumn{8}{|l|}{ Previous Use of Same Drug } \\
\hline 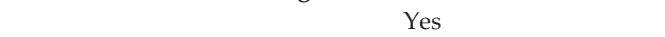 & 185 & 47.2 & 86 & 46.5 & - & 1 & - \\
\hline No & 207 & 52.8 & 133 & 64.3 & $0.000^{*}$ & 2.069 & $1.380-3.103$ \\
\hline \multicolumn{8}{|l|}{ Number of Drugs Prescribed } \\
\hline 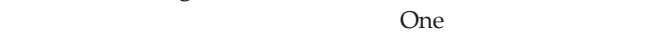 & 180 & 45.9 & 92 & 51.1 & - & 1 & - \\
\hline Two-four & 193 & 49.2 & 115 & 59.6 & 0.321 & 0.61 & $0.230-1.620$ \\
\hline More than four & 19 & 4.8 & 12 & 63.2 & 0.762 & 0.86 & $0.324-2.281$ \\
\hline \multicolumn{8}{|l|}{ PHYSICIAN RELATED FACTORS } \\
\hline \multicolumn{8}{|l|}{ Doctor } \\
\hline General Practitioner & 99 & 25.3 & 64 & 64.6 & - & 1 & - \\
\hline Specialist & 293 & 74.7 & 155 & 52.9 & $0.043^{*}$ & 1.628 & $1.016-2.609$ \\
\hline \multicolumn{8}{|l|}{ Place of Consult } \\
\hline Private Clinic & 98 & 25 & 51 & 52 & - & 1 & - \\
\hline Government Hospital & 98 & 25 & 48 & 49 & 0.389 & 0.781 & $0.444-1.372$ \\
\hline Local Health Center & 98 & 25 & 63 & 64.3 & 0.198 & 0.691 & $0.393-1.214$ \\
\hline Private Hospital & 98 & 25 & 57 & 58.2 & 0.38 & 1.295 & $0.728-2.303$ \\
\hline \multicolumn{8}{|l|}{$\underline{\text { PRESCRIPTION RELATED FACTORS }}$} \\
\hline \multicolumn{8}{|l|}{ Prescription Type } \\
\hline Single prescription with single drug & 180 & 45.9 & 92 & 51.1 & - & 1 & - \\
\hline Single prescription with multiple drugs & 150 & 38.3 & 94 & 62.7 & 0.719 & 0.836 & $0.316-2.216$ \\
\hline Multiple prescriptions with single drug per prescription & 44 & 11.2 & 23 & 52.3 & 0.558 & 1.343 & $0.501-3.602$ \\
\hline Multiple prescriptions with multiple drugs per prescription & 18 & 4.6 & 10 & 55.6 & 0.814 & 0.876 & $0.291-2.637$ \\
\hline Legibility: Patient Can Read the Prescription Without Diffic & & & & & & & \\
\hline Yes & 280 & 71.4 & 128 & 45.7 & - & 1 & - \\
\hline No & 112 & 28.6 & 91 & 81.3 & $0.000^{*}$ & 5.146 & $3.030-8.738$ \\
\hline Prescription Contains the Complete Information Required $b$ & aw & & & & & & \\
\hline Yes & 90 & 23 & 48 & 53.3 & - & 1 & - \\
\hline No & 302 & 77 & 171 & 56.6 & 0.581 & 1.142 & $0.712-1.832$ \\
\hline Prescription Contains a Complete Set of Instruction for Prop & Drug In & & & & & & \\
\hline Yes & 84 & 21.4 & 33 & 39.3 & - & 1 & - \\
\hline No & 308 & 78.6 & 186 & 60.4 & $0.001^{*}$ & 2.356 & $1.438-3.861$ \\
\hline
\end{tabular}


Table 2. Proportions of the Six Parameters of Complete Understanding Missed Out by the Patients

\begin{tabular}{lcc}
\hline \multicolumn{1}{c}{ Parameter } & Missed Out (n) & n (\%) \\
\hline Name of the Drug & 103 & 26.3 \\
Route of Administration & 10 & 2.6 \\
Formulation & 14 & 3.6 \\
Dose & 176 & 44.9 \\
Frequency & 34 & 8.7 \\
Duration & 60 & 15.3 \\
\hline
\end{tabular}

The proportions of participants with incomplete understanding of prescriptions across age groups range from $46.3 \%$ to $60.0 \%$. Male population $(59.8 \%$ ) has a higher proportion of incomplete understanding of prescriptions as compared to females $(54.2 \%)$. It is important to note that there is an inverse relationship between the level of educational attainment and the proportions of patients with incomplete understanding of prescriptions. Of the 264 married patients, $140(53.0 \%)$ had an incomplete understanding of the prescriptions and these proportions did not differ between the employed and unemployed participants $(58.9 \%$ vs $54.4 \%)$, between those who were using and not using other drugs (53.1\% vs $57.8 \%$ ). Higher proportions of incomplete understanding were identified among participants who never had any experience of drug administration to another patient (62.6\%). Among the 180 patients prescribed with a single drug, 92(51.1\%) had an incomplete understanding of the prescriptions which did not significantly differ among those prescribed with 2-4 drugs and more than four drugs (59.6\% and 63.2\%). Among the 185 patients who had a previous use of the same or similar prescribed drug, $86(46.5 \%)$ had an incomplete understanding of the prescriptions.

Patients who consulted general practitioners (64.6\%) had higher proportions of incomplete understanding of prescriptions as compared to specialists (52.9\%). Among the different places of consult, local health centers $(64.3 \%)$ had the highest proportion of incomplete understanding of prescriptions with government hospitals (49.0\%) as the lowest.

Participants who had single prescriptions containing multiple drugs $(62.7 \%)$ were found to have a higher proportion of incomplete understanding. This is also noted among participants whose prescriptions did not contain complete instructions regarding proper intake of prescribed drug (60.4\%), non-legible prescriptions (81.3\%), and prescriptions not conforming to provisions of the law, RA $9521(56.6 \%)$.

The binary logistic regression analysis provides estimates of the degree to which certain categorical predisposing variables influence patients' incomplete understanding of prescriptions. Results from the logistic regression model in Table 1 suggest that, compared with results from married participants, the odds of incomplete understanding of prescriptions were 0.396 times lower $(95 \%$
CI 0.162-0.967) among single participants and 0.297 lower (95\% CI 0.091-0.962) for participants with live-in partners.

The odds of incomplete understanding of prescriptions were 2.069 times higher (95\% CI 1.380-3.103) among patients with no previous use as compared to those who had a previous use of the prescribed drug. Compared with the results from legible prescription, the odds of incomplete understanding of prescriptions were 5.146 times higher $(95 \%$ CI 3.030-8.738) among non-legible prescriptions. An odds ratio of 1.628 times higher (95\%CI 1.016-2.609) was also identified among specialists than general practitioners in incomplete understanding of prescriptions. Patients whose prescriptions did not contain a complete set of instructions regarding the proper intake of prescribed drugs had an odds ratio of 2.356 times higher (95\% CI 1.438-3.861) compared to prescriptions complete written instructions.

A number of other variables were notable for their lack of statistical significance and these include age, sex, educational attainment, marital status, occupation, use of other drugs, experience of drug administration, prescription type, number of drugs prescribed, type of doctor and place of consult.

Multivariate logistic regression analysis in Table 3 identified only three independent variables to be statistically significant predisposing factors to incomplete understanding of prescriptions: no previous use of the prescribed drug (OR=2.126, 95\% CI 1.361-3.320), non-legible prescriptions (OR=4.598, 95\% CI 2.671-7.913) and incomplete set of written instructions regarding proper intake of the prescribed drug (OR=2.108, 95\% CI 1.234-3.601).

Table 3. Multivariate Logistic Regression Analysis of the Factors Affecting Patient's Inability to Understand Prescriptions as Initially Determined by Preliminary Binary Logistic Regression Analysis.

\begin{tabular}{|c|c|c|c|}
\hline $\begin{array}{c}\text { Categorical Predisposing } \\
\text { Factors }\end{array}$ & p-value & $\begin{array}{l}\text { Odds } \\
\text { Ratio }\end{array}$ & $\begin{array}{c}95 \% \\
\text { Confidence } \\
\text { Interval }\end{array}$ \\
\hline \multicolumn{4}{|l|}{ Marital Status } \\
\hline Married & - & 1 & - \\
\hline Single & 0.283 & 0.564 & $0.198-1.603$ \\
\hline Separated & 0.756 & 0.832 & $0.262-2.646$ \\
\hline Widow/Widower & 0.683 & 1.417 & $0.266-7.543$ \\
\hline Live-in & 0.351 & 0.523 & 0.134-2.041 \\
\hline \multicolumn{4}{|l|}{ Previous Use of Same Drug } \\
\hline Yes & - & 1 & - \\
\hline No & $0.001^{*}$ & 2.126 & $1.361-3.320$ \\
\hline \multicolumn{4}{|c|}{ Legibility: Patient Can Read the Prescription Without Difficulty } \\
\hline Yes & - & 1 & - \\
\hline No & $0.000^{*}$ & 4.598 & 2.671-7.913 \\
\hline \multicolumn{4}{|c|}{ Prescription Contains a Complete Set of Instruction for Proper Drug } \\
\hline Yes & - & 1 & - \\
\hline No & $0.006^{*}$ & 2.108 & 1.234-3.601 \\
\hline \multicolumn{4}{|l|}{ Doctor } \\
\hline $\begin{array}{l}\text { General } \\
\text { Practitioner }\end{array}$ & - & 1 & - \\
\hline Specialist & 0.361 & 1.307 & $0.736-2.322$ \\
\hline
\end{tabular}




\section{Discussion}

The patients' understanding of the doctor's prescription is one of the essential elements towards a successful treatment. Previous studies have already demonstrated the close relationship between understanding of prescriptions and treatment compliance. . $^{410}$

In this study, $55.9 \%$ of the study population had an incomplete understanding of prescriptions. Whether one finds it alarming that only about $50 \%$ of the population can understand the doctor's prescription, similar proportions have been shown in other studies conducted in other countries. ${ }^{6,2,14}$ Most patients who do not understand the prescription report ending up asking the pharmacist to explain to them the doctor's prescription. Pharmacists have the professional responsibility of explaining to the patient the correct way of using the medicine in accordance to the treatment regimen described in the prescription, including counseling the patient about information relevant to the medicine to be administered. However, prescriptions are not only written for the pharmacists who dispense the drugs. The signa part of the prescription serves as a guide for patients who will take the drug. Moreover, it is also important to note that there is no one parameter included in the study that was not missed by the respondents, with the dose of the drug being the most commonly missed parameter. Not knowing the dose of the medication may not pose any risk for some patients but for those who are taking drugs with narrow therapeutic index, the $55.9 \%$ finding in this study should be noted by any vigilant physician who cares for their patient.

The other objective of this study is to identify the factors which significantly affect the patients' understanding of prescriptions. Of the fifteen different variables identified in this study, there were only three independent variables, which were found to be statistically significant in predisposing factors to having an incomplete understanding of prescriptions. Two of which were prescription-related factors and one patient-related factor. A non-legible prescription was the strongest predictor of incomplete understanding $(\mathrm{OR}=4.598,95 \%$ CI 2.671-7.913). Poor penmanship is a serious problem, which can lead to fatal errors. ${ }^{15}$ This problem has long been condemned and several strategies have already been done to address it yet in this study $28.6 \%$ of the study population found the prescription non-legible.

The other significant physician-related factor is the incomplete set of written instructions on the prescription $(\mathrm{OR}=2.108,95 \%$ CI 1.234-3.601). In this study, only $23 \%$ of the prescriptions had a complete set of instruction, which is only about half of the proportion reported in a study conducted in the United States. ${ }^{16}$ Some prescriptions just contained the name of the drug while others still had Latin abbreviations, which the patients could not understand. Most prescriptions contained incomplete instructions, which would just be compensated by the verbal instructions of the doctors. Sano et al. states that if instructions are given only verbally, the patient will likely forget it or mix things up. ${ }^{11}$ Each prescription should contain a complete set of step-by-step instruction- from the name of the drug to the route of administration, dose, formulation, frequency, and durationand these instructions should be understood by any patient of whatever level of educational attainment. However, written instructions should not be used as a substitute for counseling and patient education. ${ }^{2}$ In other words, verbal and written instructions serve to complement each other. In addition, physicians also benefit from writing a complete set of instructions because this will also serve as a guide for the doctor in finding out the cause of a possible treatment failure. Furthermore, Section 3.4 of Administrative Order No. 62 (1989) requires all prescriptions to contain the name of the drug, the manufacturer, brand name if desired, dose, and delivery mode. It does not require the writing of the formulation, frequency and duration of drug intake. The findings in our study may be used by the health policy makers in the country to amend this law to further enhance good prescription writing.

Patients who had no previous use of the prescribed drug were found to be twice as likely to have an incomplete understanding of prescriptions (95\% CI 1.361-3.320) as compared to those who have already used the drug or a similar drug before. Similar findings have been shown in the study by Sung et al, where patients with chronic diseases who are on maintenance medications are more likely to understand prescriptions better. ${ }^{17}$ While this has been shown to be a risk for non-persistence in another study, our study has shown that it is protective for incomplete understanding, and subsequently non-compliance. ${ }^{1}$ Together with acceptance, persistence and compliance are the three main aspects of patient adherence. Compliance refers to patients taking the prescribed medication correctly while persistence is defined as the continued renewal of the prescription in accordance with the treatment duration. ${ }^{18}$ This, therefore, means that physicians should be more patient and careful in instructing and educating patients who will take the prescribed drug for the first time.

The other twelve factors lacked statistical significance in affecting the patients' understanding of a prescribed drug. Most of these are demographic factors, such age, sex, civil status, occupation and even the patient's educational attainment. These patient related factors were also found to be not significant in other studies except for the patient's educational attainment, which was found to be significant in other studies. $3,11,17,19-21$ One probable reason for this is that $87.5 \%$ of the study population had at least a high school education, which might already be sufficient to understand the instructions for drug intake. Patient counseling and a complete step-by-step written instruction will make it easier for patients to understand prescriptions, regardless of their 
educational attainment. ${ }^{11}$ In this study, all 392 patients reported that they were advised by their physician; this might have compensated their supposed inadequate education. Marital status was also not found to be significant, contrary to the findings of the study conducted by Cramer et al. ${ }^{22}$ Furthermore, although the proportion of patients with incomplete understanding are higher among patients without the use of other drugs other than the currently prescribed medications and in those without experience of administering a drug to a sick family member or any other patient, these were not found to be significant, unlike the findings of Cramer et al. ${ }^{22}$

Another remarkable finding in this study is that the number of drugs prescribed was not found to be statistically significant to affect the patients' understanding of prescriptions. Previous studies have shown conflicting results. Older studies showed an inverse relationship between the number of drugs prescribed and compliance whereas recent studies showed otherwise. ${ }^{18,23-27}$

As to the physician related factors, a consult with a general practitioner was found to have a higher proportion of incomplete understanding but this was not statistically significant after considering the other factors in the multivariate analyses. Similar findings were also shown in the analyses of the place of consult where consults done at a local health center were found to have higher proportions of incomplete understanding but this was not statistically significant even at the a priori level.

The type of prescription was not found to be statistically significant. This finding is important for the health policy makers in the country. Administrative Order No. 62 issued in 1989 considered writing more than one drug product in one prescription as erroneous. However, the year after, Administrative Order No. 90 was made to amend the previous law, permitting doctors to write more than one drug in one prescription form. The findings in this study, therefore, support the latter provision. Moreover, the technical requirements of RA 5921, which mandates all prescriptions to contain the name of the prescriber, office address, professional registration number, professional tax receipt number, patient's/ client's name, age and sex, was also not found to be statistically significant. Nevertheless, this is still important in preventing the dispensing of medications without a prescription and in complying with the requirements of other laws, which requires a complete prescription to avail of discounts, for example to senior citizens.

Ethical issues were also encountered during the conduct of the study. This was the case of a seaman being prescribed with Atenolol $50 \mathrm{mg}$ once a day for 5 days to reportedly lessen the patient's blood pressure so that he may pass the pre-employment check-up when he comes back to the doctor. The patient was also prescribed with 1 tablet of Losartan (50 mg) and 1 tablet of Amlodipine (5 mg), which were to be taken on the day of his follow-up. Any medical student who has been through Clinical Pharmacology knows that this is undoubtedly a case of irrational drug use. In compliance with the ethical responsibility of our research, we advised the patient to seek consult with another physician after explaining the possible harm of the improper use of these anti-hypertensive medications. Another case would be that of a few patients who reported planning to buy only a part of the number of pills prescribed due to financial constraints. These patients were carefully advised about the risk of not complying with the treatment duration. No monetary donation was given to these respondents.

\section{Conclusion}

In promoting the improvement of medical care in the country, this study assessed the understanding of Filipino patients regarding the drugs prescribed by their doctors. A successful treatment regimen starts with the patient accepting the regimen, then complying with the current prescription and finally continuing the proposed management thereafter. Our study focused on the patients' compliance with the current prescription. The various factors which were deemed to affect their understanding were then identified to ascertain the populations at risk of non-compliance.

The results of this study suggest that physicians play an important role in promoting a complete understanding of prescriptions. Non-legible prescriptions and prescriptions with an incomplete set of written instructions were found to significantly affect the patients' understanding of prescribed drugs. Physicians should also be more careful in instructing patients who will take the prescribed medications for the first time. These information may be used to target the populations at risk of having an incomplete understanding of prescriptions, which subsequently leads to noncompliance and eventually, to possible treatment failure.

\section{References}

1. Osterberg L, Blaschke T. Adherence to medication. N Engl J Med. 2005; 353(5):487-97.

2. World Health Organization. Adherence to Long-Term Therapies: Evidence for Action. WHO Publication. 2003

3. National Council on Patient Information and Education. Enhancing Prescription Medicine Adherence: A National Action Plan. 2007

4. Lau HS, Beuning KS, Postma-Lim E, Klein-Beernink L, Boer A, Porsius AJ. Non-compliance in elderly people: evaluation of risk factors by longitudinal data analysis. Pharm World Sci. 1996; 18(2):63-8.

5. Davis TC, Federman AD, Bass PF, et al. Improving patient understanding of prescription drug label instructions. J Gen Intern Med. 2009; 24(1):57-62.

6. Gottlieb H. Medication nonadherence: finding solutions to a costly medical problem. Drug Benefit Trends. 2000; 12(6):57-62.

7. Kirsch I, Jungeblut A, Jenkins L, Kolstad A. Adult Literacy in America: A First Look at the Results of the National Adult Literacy Survey. Washington: Department of Education, National Center for Education Statistics. 1993. 
8. Hardon A. Confronting IIl health: Medicines, Self-care and the Poor in Manila. Quezon City. Health Action Information Network. 1991.

9. Hardon A, Hodgkin C, Fresle D. How to Investigate the Use of Medicines by Consumers. World Health Organization and University of Amsterdam. 2004.

10. Lansang MA, Lucas-Aquino R, Tupasi TE, et al. Purchase of antibiotics without prescription in Manila, the Philippines. Inappropriate choices and doses. J Clin Epidemiol. 1990; 43(1):61-7.

11. Sano PY, Masorti RR, dos Santos AAC, Cordeiro JA. Evaluation of the understanding level of pediatric prescription. Jornal de Pediatria. 2002; 78(2):140-5.

12. Cohen ML. Mercury Drug Corporation from Reference for Business: Encyclopedia of Business, 2nd ed. [Online]. 2010 [cited 2010 May]. Available from http://www.referenceforbusiness.com/history/LoMe/Mercury-Drug-Corporation.html.

13. Ragaza JM, Morales A. Botika ng Barangay Drug Prices Can Still Be Lower from Vera Files [Online]. 2009 [cited 2010 May]. Available from http://verafiles.org/main/focus/botika-ng-barangay-drug-prices-can-stillbe-lower/.

14. Kramer JM, Hammill B, Anstrom K, et al. National evaluation of adherence to beta blocker therapy for 1year after acute myocardial infarction in patients with commercial health insurance. Am Heart J. 2006; 152(3):454.e1-8.

15. Akoria OA, Isah AO. Prescription writing in public and private hospitals in Benin City, Nigeria: the effects of an educational intervention. Can J Clin Pharmacol. 2008; 15(2):295-305.

16. US Food and Drug Administration. Medicine Information Received by Consumers. U.S. Food and Drug Administration [Online]. 2006 [cited 2010 May]. Available from http://www.fda.gov/cder/Offices/ ODS/y2ktitle.htm

17. Sung JC, Nichol MB, Venturini F, Bailey KL, McCombs JS, Cody M. Factors affecting patient compliance with antihyperlipidemic medications in an HMO population. Am J Manag Care. 1998; 4(10):142130.

18. Fletcher SW, Fletcher RH, Thomas DC, Hamman C. Patients' understanding of prescribed drugs. J Community Health. 1979; 4(3):1839.

19. Beardon PH, McGilchrist MM, McKendrick AD, McDevitt DG, MacDonald TM. Primary non-compliance with prescribed medication in primary care. BMJ. 1993; 307(6908):846-8.

20. Williams MV, Parker RM, Baker DW, et al. Inadequate functional health literacy among patients at two public hospitals. JAMA. 1995; 274(21):1677-82

21. Kalichman SC, Ramachadran B, Catz S. Adherence to combination antiretroviral therapies in HIV patients of low health literacy. J Gen Intern Med. 1999; 14(5):267-73.

22. Cramer J, Rosenheck R, Kirk G, Krol W, Krystal J. Medication compliance feedback and monitoring in a clinical trial: predictors and outcomes. Value Health. 2003; 6(5):566-73.

23. Taylor DW, Sackett DL, Haynes RB, Johnson AL, Gibson ES, Roberts RS. Compliance with antihypertensive drug therapy. Ann N Y Acad Sci. 1978; 304:390-403

24. Sclar DA, Chin A, Skaer TL, Okamoto MP, Nakahiro RK, Gill MA. Effect of health education in promoting prescription refill compliance among patients with hypertension. Clin Ther. 1991; 13(4):489-95.

25. Monane M, Bohn RL, Gurwitz JH, Glynn RJ, Levin R, Avorn J. The effects of initial drug choice and comorbidity on antihypertensive therapy compliance: Results from a population-based study in the elderly. Am J Hypertens. 1997; 10(7 Pt 1):697-704.

26. Shalansky SJ, Levy AR. Effect of number of medications on cardiovascular therapy adherence. Ann Pharmacother. 2002; 36(10):1532-9.

27. Grégoire J, Moisan J, Guibert R, Ciampi A, Milot A. Predictors of selfreported noncompliance with antihypertensive drug treatment: a prospective cohort study. Can J Cardiol. 2006; 22(4):323-9. 
Appendix

Researcher Structured Questionnaire

Note:

1. Font size of the questionnaire was adjusted to fit in the page.

2. During the conduct of the interview, it was the interviewer, and not the respondent, who filled out the questionnaire.

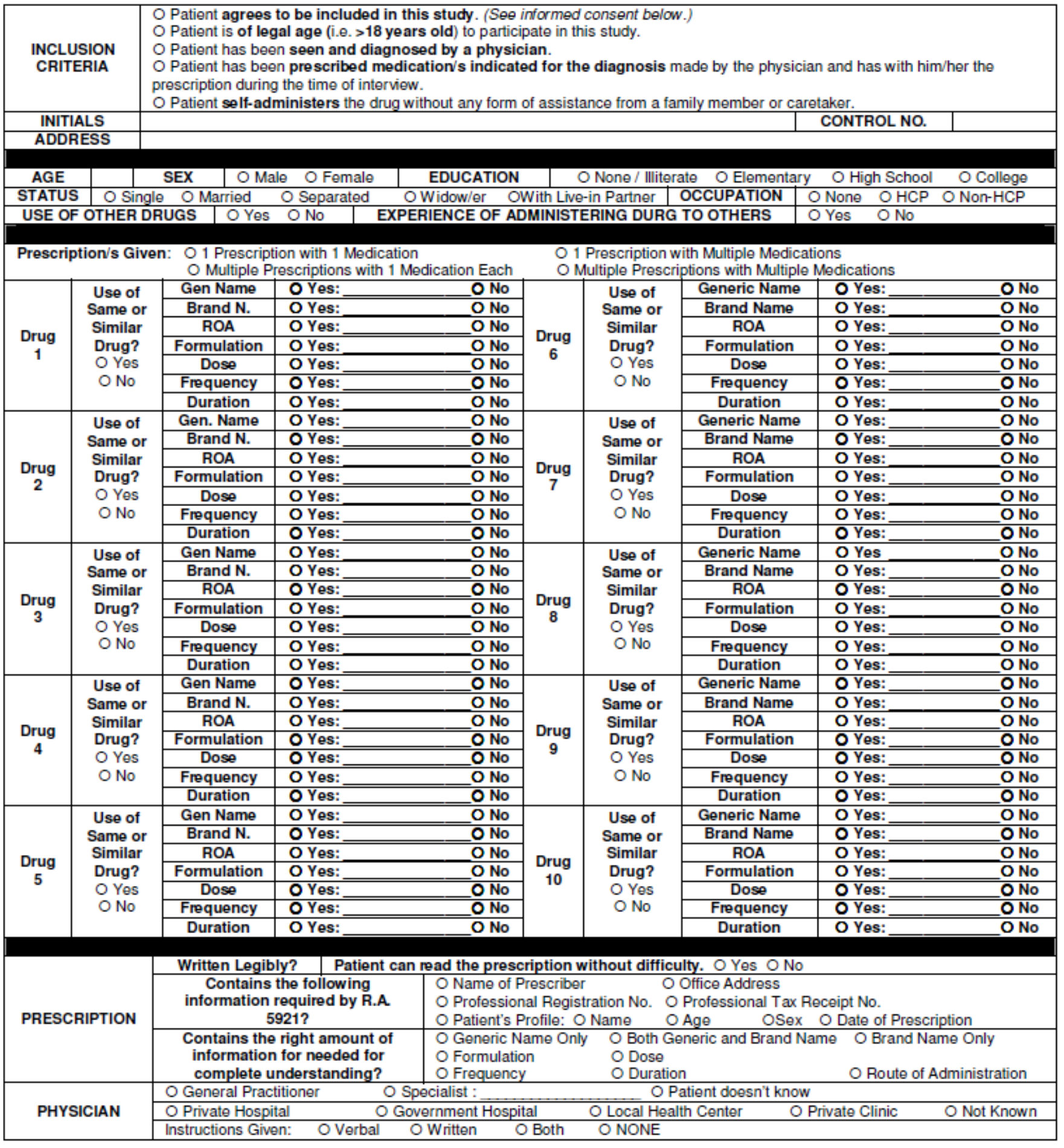

* Legend: HCP- Health Care Professional; Non-HCP- Non-Health Care Professional; ROA- route of administration 